\title{
COMMENTARY
}

\section{DEVELOPMENTS IN AMINO ACID TRANSPORT, ILLUSTRATED FOR THE BLOOD-BRAIN BARRIER}

\author{
HALVOR N. Christensen \\ Department of Biological Chemistry, The University of Michigan, Ann Arbor, MI 48109, U.S.A.
}

\begin{abstract}
The part played by membrane transport of metabolites in the regulation of metabolism is so extensive and widespread that I would offer a tedious catalog if I discussed the full range. Instead, the problem of the regulation of tryptophan access to the central nervous system has been selected as an example. I should be grateful if this summary brought to mind other cases, such as the more complex problems of membrane control of the flow of amino acids, first to the liver (e.g. from the portal system for temporary holding and interconversion, or from muscle for gluconeogenesis), and then away from the liver (e.g. to supply the other tissues of the body with the various amino acids in some degree of balance). Reference may also be made to the classical discussion of membrane transport in pharmacology by Wilbrandt and Rosenberg [1].
\end{abstract}

In this decade. two techniques have contributed to the study of metabolite flow to the brain. Oldendorf [ 2 ] introduced direct analysis of uptake by rat brain, during a single circuit from a "bolus" or pulse, of a labeled metabolite injected into carotid blood, compared with simultaneous uptake of tritiated water. The other technique, applicd typically to the dog, mcasures the clcarance of a solute, using the arteriovenous difference determined by cannulation and without brain analysis $\{3,4]$.

Using Oldendorf's technique, Wade and Katzmann [5] showed that amino acids which pass rapidly across the blood-brain barrier are those which are transported most rapidly by transport system $L$. This transport system has been described by our laboratory during the past 15 years $[6,7]$. It is a ubiquitous system which, although active for most of the amino acids, favors transport into cells of amino acid with largely apolar, sometimes bulky sidechains, e.g. phenylalanine, tyrosine, tryptophan, leucine, isoleucine, val ine, methionine and glutamine. The transport is $\mathrm{Na}^{+}$-independent, in contrast to several other systems for neutral amino acids. The pattern of uptake, as studied by Wade and Katzmann, included 2-aminonorbornane-2-carboxylic acid, developed by us as a model substrate acceptable, because of its bulk, only to system $L$ in most of the cases tested [ 8$]$. Very low clearances were shown by the model substrate recommended for system $A$, the principal $\mathrm{Na}^{+}$-dependent transport system, namely by 2 (methylamino)-isobutyric acid [5], but also by glycine and other amino acids that strongly prefer system $A$. Cells responsible for specific transport across the blood-brain barrier are thought to be capillary endothelial cells, and to some degree cells of the choroid plexus, glial cells and even neurons.

We should retain two reservations: (1) the total absence of system $A$ and similar systems on the blood side of the blood-brain barrier has not been shown; and (2) even if system $A$ is not present, alanine, serine, glutamine and glycine are not necessarily prevented from passing slowly into the brain. These amino acids characteristically have some reactivity with system $L$, and besides, all amino acids show slow passage into various cells by a non-specific, difficultly saturable route. It is not clear whether exchange by system $L$, which might be in great contrast to the net uptake of non-exchanging amino acids, has been corrected for completely.

Cutler and Coull |9| have made the interesting proposal that the near absence of a blood-to-brain flow, identifiable with system $A$, might be due to an opposite orientation of system $A$ to produce transport from the cerebrospinal fluid and brain into the blood, there being evidence for transport of some amino acids in that direction. Betz and Goldstein [10] have demonstrated recently that capillaries isolated from the rat brain show a $\mathrm{Na}^{+}$-dependent uptake of 2-(methylamino)-isobutyric acid. They propose that this uptake is restricted to the outward (brain) side of the endothelial cells, and hence produces a one-way flow, corresponding to the proposal of Cutler and Coull.

The pattern of transport across the blood-brain barrier is entirely different from that of uptake by brain slices, in which several $\mathrm{Na}^{+}$-dependent systems play a large part. Contributions of these systems are probably involved in the central inhibitory and stimulatory actions of several amino acids, and apparently they can also be involved in dietary production of low brain threonine levels $[11 \mid$.

If the uptake of a solute into cells separating two phases, such as epithelial or capillary endothelial cells, is going to produce a flow across the cells, an imbalance must be introduced in the uptake from the two surfaces of the cell layer. This imbalance for epithelial cells is often produced by an asymmetry in the distribution of the transport-producing agents between the two surfaces $\mid 12,13]$, the more steeply uphill agents lying on the low-concentration side. For example, in renal tubular epithelium, the more steeply concentrative $\mathrm{Na}^{+}$ dependent agencies are more numerous on the brushborder surface, whereas the more weakly concentrative transport agencies are more abundant on the basolateral surfaces of the cell. If net transport across the bloodbrain barrier were to be explained satisfactorily by a 
single transport system, the asymmetry must, in this case, have a different origin; it could arise from the net utilization of amino acids in the brain.

When interpreting the paper of Cutler and Coull and that of Betz and Goldstein, we should remember that even steeply concentrative transport systems must and do operate to some extent in both directions, and also that net transport can, in fact, occur from the high- to the low concentration side, as it does from the liver cell in the post-absorptive state. During the interval until the next meal, the liver serves as a source of most amino acids for other tissues. Nevertheless, the transport process, in the meantime, keeps hepatic levels typically much higher than plasma levels. The transport polarity of the capillary endothelial cells of the blood-brain barrier deserves direct determination, both as to gradients and as to net flows. Even if any or all of the neutral amino acids prove to have steady state gradients facing from the brain interstitial fuid toward the blood, it does not necessarily introduce difficulties for the brain in getting these amino acids. The actual rates of net migration into the brain of amino acids closely indentified with system $A$ need further study. If system $A$ does operate exclusively from the brain side of the endothelial cells, it would still probably cause a flow of its substrates across the cells to the blood. A precisely balanced uptake from both sides of these cells would avoid net transport and yet also nourish the cells. Furthermore, attention should be given to the effect on system $L$ transport of the presumed operation of $A$ from only one side. The amino acids which are pumped into endothelial cells will probably exchange for amino acids that are characteristically better substrates of system $L$, thereby secondarily energizing that system (see diagram in Ref. 14). This phenomenon, to be discussed in the next paragraph, seems likely to raise the amino acid content of these cells and to increase, by system $L$, at least the exchange fluxes of the latter amino acids across the blood-brain barrier. The exchange flux may be physiologically important to the degree that it occurs between any two nonidentical amino acids.

Let us examine further the interactions that can be expected between parallel transport systems. Characteristically, amino acids are conducted across plasma membranes of various cells by two or more apparently independently energized transport systems. For the Ehrlich cell we have shown that amino acids are effectively introduced into the same cellular compartment by systems $A$ and $L|15|$. presumably into the cytoplasm. Because for each amino acid one of the systems is able to produce a higher gradient than the other. and because exhange of one amino acid for another across the membrane occurs mainly by one of these systems, a steady state arises by which many of the amino acids enter the cell largely by one transport system and leave largely by another [15]. This interaction between the transport systems becomes part of the description of transport and its regulation. As mentioned already, passage of amino acids across the blood-brain barrier may be expected to show special features if, as proposed [5], only one transport system plays any significant part, or if as also proposed $[10 \mid$, one of the systems operates from only one side of the barrier.

Even though the role of membrane transport has been studied much longer in gastroenterology, nephrology, hepatic function and other clinical domains, neuropsychiatry may come to anticipate these fields in the therapeutic gains realized from the study of amino acid transport. This advantage may arise from a readier grasp of the idea that for the brain, as well as for other systems, transport across the plasma membrane determines transcellular movements of solutes.

The several metabolic fates of tryptophan in the brain, the regulation of which has important therapeutic possibilities for psychiatry, will not be discussed here, because others have done so (see ref, 16) very competently.

All investigations have shown that, if other factors are equal, plasma tryptophan concentration determines the rate of tryptophan entry into brain. If, however plasma tryptophan is raised by high protein feeding, a decrease of brain tryptophan is likely to result. The explanation lies in a very important feature of amino acid transport. Characteristically, a considerable number of amino acids compete for passage in any one of the major systems. It is necessary to think of an acceptor site for transport which is momentarily occupied by any amino acid it recognizes, such that competitive kinetics arise. The situation resembles that at the quite different reactive site of an enzyme. Feeding extra protein tends to elevate the levels of the branched-chain amino acids to such a degree that, in this competition for transport, they dominate over the increase in the concentration of tryptophan itself [17.18]. Therefore, high protein feeding actually lowers the entry of tryptophan into the brain.

This route of amino acid passage into the brain is also highly vulnerable to competitive inhibition by elevated phenylalanine levels, such as are maintained in phenylketonuria. In a discussion in $1953 / 19 /$ of competition for amino acid transport, it was written, "In certain enzyme deficiencies, for example in oligophrenia phenylpyruvica, the organism in unable to rid itself of the accumulated excess of an amino acid. The effect of such a persistent accumulation upon cell nutrition deserves attention." This explanation suggested for the poor development of the brain during infancy in phenylketonuria (PKU) has had experimental support $[20,21]$ and an important degree of acceptance $[22,23]$, although in the meantime other explanations have been under consideration. Kaufman [23] has reviewed observations on the questions as to which free amino acids have decreased levels in the brain in phenylketonuria and in sustained experimental hyperphenylalaninemia. He considers the possibility that PKU might be treated more simply with amino acid supplements instead of the present demanding program of sub-total phenylalanine restriction. Achievement of balance among the amino acids by supplementation would certainly involve a number of considerations. A recent study showed that a supplement of $3 \%$ isoleucine alone produced some enhancement toward control levels for fetal brain weights in pregnant rats [24]. Even if this effect were considered sufficient, extension of this result to the phenylketonuric infant could be perilous-through species differences the supply of tryptophan to the brain might be further endangered by the elevation of isoleucine along with phenylalanine. The access to the brain of tyrosine for synthesis of catecholamines also appears to be a 


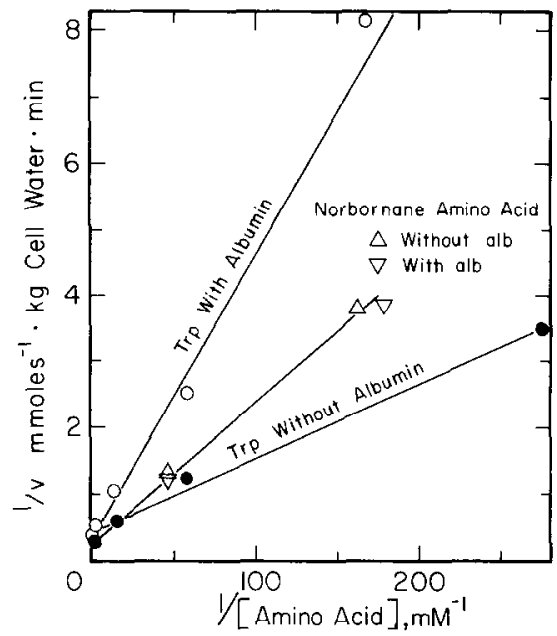

Fig. 1. Contrasting effects of $4 \%$ bovine serum albumin on the uptake of $\mathrm{t}$-tryptophan and $\mathrm{b}( \pm)$-2-aminonorbornane-2-carboxylic acid by the Ehrlich cell. The data points for the norbornane amino acid concentrations at about 0.3 and $1 \mathrm{mM}$ fell nearly on the same line as the lower concentrations, but have been omitted for clarity. Also, a consistent result for $0.3 \mathrm{mM}$ tryptophan in the absence of albumin has been omitted for lack of space. The change in apparent $K_{m}$ for uptake corresponds to 86 per cent binding of tryptophan at $0.03 \mathrm{mM}$ by albumin at $4 \%$.

vulnerable point in amino acid transport across the blood-brain barrier.

A form of phenylketonuria arising from a deficiency of endogenous biopterin [25] and another due to a deficiency of dihydropteridine reductase [26] have now been described. In treatment. phenylalanine restriction is combined with administration of dopa and 5hydroxytryptophan. the latter compounds in compensation for a presumed deficiency of hydroxylating activity in the brain. since phenylalanine restriction alone did not prevent neurologic impairment.

Tryptophan transport from the blood stream is also subject to regulation by specific binding to plasma albumin [27]. as discovered by McMenamy and Oncley [28]. Typically. 80-90 per cent of the plasma amino acid is bound in this way. Although the matter is controversial, no evidence seems to have been obtained that the albumin-bound tryptophan exerts direct mass action to drive tryptophan transport into the brain, as free tryptophan does. In experiments only now published in detail, we found that albumin-bound tryptophan, in contrast to free tryptophan, appears to be excluded from in vitro action with the transport systems of the Ehrlich ascites tumor cell and of the rat hepatocyte in primary culture (see Fig. 1, Table 1, and Ref. 15). Because of its uptake of serum albumin, one might expect that the liver cell would be able to receive albumin-bound tryptophan advantageously; however, on addition of $4 \%$ albumin to the suspending medium we found a decrease in tryptophan uptake by the rat hepatocyte in primary culture to the degree predicted if albumin-bound tryptophan were unavailable.

The binding of the amino acid to the receptor of the blood-brain barrier is. however. tighter than that to albumin. Therefore, tryptophan can be stripped from the albumin-bound form by that transport system $[16,27,29]$. This release seems likely however, to occur only to the extent that the tryptophan level is lowered during the passage of the blood through the brain. The extent to which the blood is normally cleared of tryptophan in the brain is not yet known. We can infer that albumin binding increases, by 5 - or 10 -fold. the quantity of tryptophan contained in the blood stream. in relation to the total action of the various competing tissues to deplete the plasma concentration. Further opportunities for the bound tryptophan to serve as an effective. rather than perhaps useless, reservoir for tryptophan in the plasma lie in the ability of unesterified fatty acids to compete with tryptophan for their common binding site on the albumin molecule. This action also means that lipolytic hormone action and various drugs can release tryptophan from its albumin-bound form to modulate its availability to the several tissues. Observations that various drugs lower brain serotonin become pertinent here (see Refs. 30 and 31 ). The place this regulation may take in psychopharmacology remains to be described.

Beyond the pharmacologic opportunities inherent in modifying transport of amino acids into the brain, the selection of therapeutic agents can be heavily conditioned by their suitability for transport. For example, whether $x$-methyldopa is an acceptable agent hinges in the first instance on a marginal suitability for absorption from the intestinal tract, which complicates the adjustment of dosage for each patient. Its efficacy depends in the next instance on its relative access, by transport, to the liver, where metabolic losses occur

Table 1. Slowing of tryptophan uptake by rat hepatocytes on albumin addition *

\begin{tabular}{|c|c|c|c|c|}
\hline & \multirow{2}{*}{$\begin{array}{l}\text { [Amino acid] } \\
(\mu \mathrm{M})\end{array}$} & \multicolumn{2}{|c|}{$V$ (nmoles/mg protein) } & \multirow{2}{*}{$\begin{array}{l}\text { \% Binding } \\
\text { suggested }\end{array}$} \\
\hline & & No albumin & $4 \%$ Albumin & \\
\hline \multirow[t]{2}{*}{ L-Tryptophan } & 50 & 0.347 & 0.072 & 80 \\
\hline & 100 & 0.550 & 0.121 & 76 \\
\hline \multicolumn{5}{|l|}{ b-2-Amino- } \\
\hline $\begin{array}{l}\text { norbornane- } \\
\text { 2-carboxylic acid }\end{array}$ & 50 & 0.193 & 0.189 & 2 \\
\hline $\begin{array}{l}\text { 2-carboxylic acid } \\
\text { 2-Aminoisobutyric }\end{array}$ & $\begin{array}{r}100 \\
50\end{array}$ & 0.338 & 0.344 & $\begin{array}{r}0 \\
10\end{array}$ \\
\hline $\begin{array}{l}\text { 2-Aminoisobutyric } \\
\text { acid }\end{array}$ & $\begin{array}{r}50 \\
100\end{array}$ & $\begin{array}{l}0.041 \\
0.080\end{array}$ & $\begin{array}{l}0.037 \\
0.071\end{array}$ & 9 \\
\hline
\end{tabular}

* One-min uptake measured from Krebs-Ringer bicarbonate medium at $37^{\circ}$. pH 7.4, by cells in primary culture on collagen plates (4-min uptake in the case of 2-aminoisobutyric acid). In agreement, comparing $K_{m}$ values for tryptophan uptake by the Ehrlich ascites tumor cell, in the absence and presence of $4 \%$ albumin, suggested 86 per cent binding. See Ref. 18. 
especially by decarboxylation, and to the brain, where enzymatic decarboxylation is considered as probably necessary to its efficacy.

Acknowledgements - Support from the Institute of Child Health and Human Development (Grant HDO 1233) of the National Institutes of Health, U.S.P.H.S., is gratefully ac knowledged. The collaboration of M. E. Handlogten on the results of Fig. 1 and Table 1 is also acknowledged.

\section{REFERENCES}

1. W. Wilhrandt and T. Rosenberg, Pharmar. Rev. 13. 109 (1961).

2. W. H. Oldendorf, Am. J. Physiol. 221, 1629 (1971).

3. D. L. Yudilevich. N. de Rosa and F. V. Sepúlveda, Brain Res. 44, 569 (1972).

4. D. L. Yudilevich and F. V. Sepúlveda, Adv. exp. Med. Biol. 69. 77 (1976).

5. L. A. Wade and R. Katzmann, J. Neurochem. 25, 837 (1975).

6. D. L. Oxender and H. N. Christensen, J. biol. Chem. 238, 3686 (1963).

7. H. N. Christensen, Biological Transport, 2nd Edn., pp. 175-98. W. A. Benjamin. Reading MA (1975).

8. H. N. Christensen, M. E. Handlogten, I. Lam, H. S. Tager and R. Zand. J. biol. Chem. 244, 1510 (1969).

9. R. W. P. Cutler and B. M. Coull, in Taurine and Neurological Disorders (Eds A. Barbeau and R. J. Huxtable. pp. 95-107. Raven Press, New York (1978).

10. A. L. Betz and G. W. Goldstein, Science 202, 255 (1978).

11. J. K. Tews, S. S. Good and A. E. Harper, J. Neurochem. 31. 581 (1978).

12. H. N. Christensen, in Transport Phenomena in the Neryous System (Eds G. Levi, L. Battistin and A. Lajtha), pp. 3-12. Plenum, New York (1976).

13. E. N. Slack, C-C. T. Liang and B. Sacktor, Biochem. biophys. Res. Commun. 77, 891 (1977).
14. H. N. Christensen, Biological Transport, 1st Edn, p. 59. W. J. Benjamin, New York (1962), [2nd Edn, p. 381 (1975)].

15. H. N. Christensen and M. E. Handlogten, J. Neural Transmission, in press.

16. E. F. Domino, in Neurotransmitter Balances Regulating Behaviour (Ed. and Pulb. E. F. Domino and J. M. Davis), pp. 185-228. Ann Arbor (1975).

17. J. D. Fernstrom and R. J. Wurtman. Science 178, 414 (1972).

18. J. D. Fernstrom and D. V. Faller, J. Neurochem. 30, 1531 (1978).

19. H. N. Christensen, A. Rev. Biochem. 22. 233 (1953).

20. F. Linaweh and M. Ehrlich, Klin. Wschr. 38. 904 (1960).

21. C. M. McKean, D. E. Boggs and N. A. Peterson, $J$. Neurochem. 15. 235 (1968).

22. W. E. Knox, in The Metabolic Basis of Inherited Disease (Eds J. B. Stanbury, J. B. Wyngaarden and D. S. Fredrickson), 2nd Edn, pp. 267, 276. McGraw Hill, New York (1966).

23. S. Kaufman, in Advances in Neurochemistry (Eds B. W. Agranoff and M. H. Aprison). Vol. 2, pp. 100-3. Plenum. New York (1977).

24. R. L. Brunner. C. V. Vorhees, M. S. McLean, R. E. Butcher and H. K. Berry, Brain Res. 154, 191 (1978).

25. S. Kaufman, S. Barlow, G. K. Summer, S. Milstien, J. D. Schulman, S. Orloff, S. Spielburg and S. Pueschel, New Engl. J. Med. 299.673 (1978).

26. S. Kaufman. N. A. Holtzman. S. Milstien. I. J. Butler and A. Krumholz, New Engl. J. Med. 293, 785 (1977).

27. A. Yuwiler, W. H. Oldendorf, E. Geller and L. Braun, J. Neurochem. 28, 1015 (1977).

28. R. H. Mc Menamy and J. L. Oncley, J. biol. Chem. 233, 1436 (1958).

29. W. M. Pardridge, J. Neurochem. 28, 103 (1977).

30. G. Curzon. Adv. Biochem. Psychopharmac. 10, 263 (1974).

31. G. L. Gessa and A. Tagliamonte, Adv. Biochem. Psycho pharmac. 11. 119 (1974). 